\title{
St John Simpson, Theya Molleson. « Old Bones Overturned. New Evidence for Funerary Practices from the Sasanian Empire »
}

\section{Rémy Boucharlat}

\author{
(2) OpenEdition \\ Journals \\ Édition électronique \\ URL : http://journals.openedition.org/abstractairanica/42569 \\ DOI : 10.4000/abstractairanica.42569 \\ ISBN : 1961-960X \\ ISSN : 1961-960X \\ Éditeur : \\ CNRS (UMR 7528 Mondes iraniens et indiens), Éditions de l'IFRI \\ Référence électronique \\ Rémy Boucharlat, « St John Simpson, Theya Molleson. « Old Bones Overturned. New Evidence for \\ Funerary Practices from the Sasanian Empire » », Abstracta Iranica [En ligne], Volume 37-38-39 | 2018, \\ document 1, mis en ligne le 10 mars 2018, consulté le 28 septembre 2020. URL : http:// \\ journals.openedition.org/abstractairanica/42569; DOI : https://doi.org/10.4000/abstractairanica \\ 42569
}

Ce document a été généré automatiquement le 28 septembre 2020.

Tous droits réservés 
St John Simpson, Theya Molleson. « Old Bones Overturned. New Evidence for Funerary Practices from the Sasanian Empire »

Rémy Boucharlat 


\section{RÉFÉRENCE}

St John Simpson, Theya Molleson. « Old Bones Overturned. New Evidence for Funerary Practices from the Sasanian Empire » in A. Fletcher, D. Antoine and J.D. Hill (eds.) Regarding the Dead: Human Remains in the British Museum, British Museum Research Publication 197, 2014, London, p. 77-90.

1 Deux cas de décharnements en Iran et en Asie centrale. Des ostothèques découvertes à la fin du $19^{\mathrm{e}}$ siècle à Bushehr, et conservées au British Museum : d'une part des jarres à vin (type torpedo jar très répandu dans tout l'Orient), réutilisées, dont le col est soigneusement cassé, datables entre le $2^{\mathrm{e}}$ et le $9^{\mathrm{e}} \mathrm{s}$. de n.è., d'autre part des petits coffres en calcaire avec couvercle, uniques en Iran ; ils sont quadrangulaires, avec l'un petits côtés arrondis, dont la longueur maximale n'excède pas $60 \mathrm{~cm}$. Les uns et les autres ont servi d'ostothèques (astodans). D'après l'analyse anthropologique, ces ossements ont bien été mis dans la jarre ou dans le coffre après décharnement. Les os longs ont été délibérément brisés, sans doute pour faciliter leur insertion dans les contenants preuve supplémentaire de cette pratique.

2 À Merv, ont été découvertes des concentrations d'ossements désarticulés, parfois brisés, pris dans une couche de sable et enfouis dans le rempart alors désaffecté. Ils correspondant à trois individus d'âges différents. Dans les deux cas, loin des habitats, ces dépôts d'ossements après décharnement correspondent bien aux pratiques zoroastriennes.

\section{AUTEURS}

RÉMY BOUCHARLAT

UMR 5133 CNRS-Université de Lyon 